\title{
AMMI and GGE biplot analysis of grain yield of bread wheat (Triticum aestivum L.) genotypes at moisture deficit environment of Wollo, Ethiopia
}

\author{
Agegnehu Mekonnen ${ }^{1 *}$, Firew Mekbib ${ }^{2}$ and Arega Gashaw ${ }^{1}$ \\ ${ }^{1}$ Crop Improvement Research Division, Sirinka Agricultural Research Center, Woldia, Ethiopia. \\ ${ }^{2}$ School of plant Sciences, Haramaya University, Dire Dawa, Ethiopia. \\ ${ }^{*}$ Corresponding author. Email: agymak2004@gmail.com
}

Copyright (C) 2019 Mekonnen et al. This article remains permanently open access under the terms of the Creative Commons Attribution License 4.0, which permits unrestricted use, distribution, and reproduction in any medium, provided the original work is properly cited.

Received 16th January, 2019; Accepted 15th February, 2019

\begin{abstract}
Twenty-two bread wheat varieties were tested at six locations of eastern Amhara region. The experiment was laid-out using Randomized Complete Block (RCB) design and replicated three times with the objective of estimating the magnitude of Genotype by Environment (GE) interactions for grain yield and stability of bread wheat genotypes. Individual environment and combined analysis of variance were carried out using Genstat software 18th edition and Least Significant Difference (LSD) was employed to separate means. Combined ANOVA for grain yield showed significant difference among genotypes, environments, and GE interactions. Genotypes G1, G9 and G16 out-smarted in grain yield, providing mean grain yield of $3.60,3.56$, and 3.55 tha $^{-1}$, respectively. The stability was measured by AMMI and GGE biplot. AMMI-1 select most adapted genotypes such as G9 and G16 for E3 and G17 for E1. G12, G6, G3, G19, G7 and G11 genotypes were suitable for all environments. AMMI-2 biplot showed E1, E5 and E6 contributed large interaction effects while E2, E3 and E4 contributed small interaction effects. GGE biplot identify G9, G16 and G19 for E1, E3, E6 and E5 and G17, G21, G14 and G15 for E1 and E4. G6, G12 and G1 genotypes were good for all environments. Thus, due attention should be given while selecting bread wheat genotypes for the target environments.
\end{abstract}

Keywords: Bread wheat, grain yield, mega-environment, stability analysis.

\section{INTRODUCTION}

Amhara National Regional State (ANRS) is one of the major wheat growing regions of Ethiopia which shared about $32.8 \%(545,106.1$ ha.) and $28.96 \%$ (1.22 million tons) of the total wheat growing area and production of the country, respectively (CSA, 2016). Of the total wheat production areas covered in the Amhara region, $25.8 \%$ of it is found in North and South Wollo zones (CSA, 2016). Productivity of wheat in South and North Wollo zones was about $1.9 \mathrm{t} \mathrm{ha}^{-1}$, less than the regional average.

The possible problems for low productivity of wheat are the use of low yielding bread wheat varieties, erratic distribution of rainfall, wheat diseases, and diverse environments within the two zones. However, since the presence of diverse agro-ecologies, information on genotype by environment (GE) interactions of bread wheat genotypes to diverse environments of moisture stressed areas of Wollo was inadequate. Grain yield is the most important agronomical and economical quantitative traits that routinely exhibit GE interactions (Fan et al., 2007). It is known that mean grain yield across environments are sufficient indicator of genotypic performance only in the absence of GE interaction (Yan and Kang, 2002). Ceccarelli (2012) and Romagosa and Fox (1993) reported that if there is cross over interaction (change in genotypes ranking) the efficiency of plant breeding activities is very limiting that poses challenges to breeders. If a change in 
ranking of genotypes over location happens consistently, then the breeding environments may be classified into mega-environments and specifically adapted varieties can be developed for each micro-environment separately (Yan et al., 2007).

Multi-Environment (ME) trials are widely used by plant breeders to evaluate the relative performance of genotypes for target environments (DeLacy et al., 1996). In $M E$ trials data, environment $(E)$ is always the predominant sources of yield variation, however, is not relevant for cultivar evaluation (Gauch and Zobel, 1996). Only $G$ and $G E$ interactions are relevant to cultivar evaluation. GE interaction is important only when it is significant and causes significant change in genotype ranking across environments (Haldane, 1946). Therefore, information on GE interactions should be handled properly (Shafii and Price, 1998)

Combined ANOVA is more often used to identify the existence of GE interactions in ME experiments. Although this analysis allows the determination of the genotype, environment, and GE interaction variances, however, it does not allow exploring the responses of the genotypes in the GE interaction (Zobel et al., 1988). Since the nonadditive structure of the data matrix has a non-random and random component, the advantage of the additive model is lost if the pattern component of the non-additive structure is not further partitioned into functions of one variable each (Crossa, 1990).

Numerous methods have been developed to reveal patterns of GE interactions and to determine the stability of genotypes across environments: joint regression (Eberhart and Russell, 1966; Finlay and Wilkinson, 1963; Perkins and Jinks, 1968), sum of squared deviations from regression (Eberhart and Russell, 1966), stability variance (Shukla, 1972), coefficient of determination (Pinthus, 1973), coefficient of variability (Francis and Kannenberg, 1978).

Among various statistical techniques used for evaluating GE interactions, AMMI (Additive Main-effects and Multiplicative Interaction) model and GGE (Genotype plus Genotype by Environment) biplot are the two most frequently used recent methods.

\section{AMMI model}

AMMI model uses ANOVA and principal component analysis to explain genotypes in ME trials (Bradu and Gabriel, 1978; Gauch and Zobel, 1988). Many investigators emphasized the AMMI model as a tool to analyze GE interaction and to define stability for each genotype (Crossa et al., 1990; Gauch and Zobel, 1988; Zobel et al., 1988). In the biplots of AMMI, the first IPCA was used as the ordinate (Y-axis) and main effects (both genotype and environment) represent the abscissa (Xaxis). Similarly, the IPCA1 as abscissa and IPCA2 as ordinate were used to further explore of the stability (Kempton, 1984).

\section{GGE biplot}

Yan et al. (2000) proposed a GGE biplot analysis derived from the first two principal component analysis (PC1 and PC2), which considers genotype (G) and GE interaction effects as important sources of variation during cultivar evaluation. The GGE biplot can be useful to display the which-won-where pattern of the data that may lead to identify high-yielding and stable cultivars and discriminating and representative test environments (Yan, 2001). It allows visual examination of the relationships among the test environments, genotypes and the GE interactions. According to Yan and Hunt 2002, the polygon view of the GGE biplot indicates the best genotype(s) in each environment and group of environments. The polygon is formed by connecting the markers of the genotypes that are furthest away from the biplot origin such that all other genotypes are contained in the polygon. The rays are lines that are perpendicular to the sides of the polygon or their extension (Yan and Kang, 2002).

Different experiments were conducted by different scientists to evaluate the performances of different wheat genotypes across different environments, reporting the complexity of GE interaction (Golkari et al., 2016; Hagos and Abay, 2013; Mehari et al., 2015; Mohamed, 2013; Mohammadi et al., 2015; Mohammadi et al., 2011; Sanchez-garcia et al., 2012; Temesgen et al., 2015).

Authors of different countries including Ethiopia used both AMMI and GGE biplot analysis to assess the GE interaction and to see performances of wheat and other crop genotypes across different environments (Abate et al., 2015; Ayalew et al., 2014; Farshadfar et al., 2012; Gebru et al., 2011; Hagos and Abay, 2013; Mohamed and Ahmed, 2013; Muhe and Assefa, 2011; Rad et al., 2013; Tadesse and Abay, 2011; Bacha et al., 2015).

The present research was carried-out to estimate the magnitude of GE interaction and determine yield stability of bread wheat varieties combining with high grain yield using AMMI and GGE biplot techniques.

\section{MATERIALS AND METHODS}

The experiment was conducted during the 2015/16 cropping season at six environments located in north eastern Ethiopia where environmental conditions are diverse in soil type, altitude, positional information, minimum and maximum temperature and amount of rainfall (Tables 1 and 2). Among the six testing environments Kon and Geregera are located in North Wollo Administrative Zone while Jamma, Woreilu, Borena and Mekdela are located in South Wollo Administrative Zone. 
Table 1. Description of the test environments.

\begin{tabular}{lllccc}
\hline Environments & Code & Soil type & Latitude & Longitude & Altitude (masl) \\
\hline Borena & E1 & Litosol & $10^{\circ} 46^{\prime} 01^{\prime \prime} \mathrm{N}$ & $38^{\circ} 49^{\prime} 55^{\prime \prime} \mathrm{E}$ & 2555 \\
Geregera & E2 & Litosol & $11^{\circ} 45^{\prime} 02^{\prime \prime} \mathrm{N}$ & $38^{\circ} 44^{\prime} 57 \mathrm{E}$ & 2872 \\
Jamma & E3 & Vertisol & $10^{\circ} 27^{\prime} 18^{\prime \prime} \mathrm{N}$ & $39^{\circ} 16^{\prime} 01^{\prime \prime} \mathrm{E}$ & 2622 \\
Kon & E4 & Litosol & $11^{\circ} 37^{\prime} 34^{\prime \prime} \mathrm{N}$ & $38^{\circ} 55^{\prime} 05^{\prime \prime} \mathrm{E}$ & 2872 \\
Mekdela & E5 & Vertisol & $11^{\circ} 57^{\prime} 21^{\prime \prime} \mathrm{N}$ & $39^{\circ} 02^{\prime} 56^{\prime \prime} \mathrm{E}$ & 2765 \\
Woreilu & E6 & Vertisol & $10^{\circ} 34^{\prime} 42^{\prime \prime} \mathrm{N}$ & $39^{\circ} 24^{\prime} 20^{\prime \prime} \mathrm{E}$ & 2628 \\
\hline
\end{tabular}

Table 2. Climate data of the test environments during the growing season of wheat in 2016.

\begin{tabular}{lccccccccc}
\hline \multirow{2}{*}{ Environments } & \multicolumn{4}{c}{ Rainfall $(\mathbf{m m})$} & \multicolumn{4}{c}{ Temperature $\left({ }^{\circ} \mathrm{C}\right)$} \\
\cline { 2 - 10 } & Jun. & Jul. & Aug. & Sept. & Oct. & Nov. & Min. & Max. & Average \\
\hline E1 & 122.7 & 176.3 & 228.8 & 80.7 & 8.5 & 0 & 10.5 & 23.1 & 16.2 \\
E2 & 81.6 & 451.5 & 297.2 & 95.6 & 1.3 & 3.3 & na & na & na \\
E2 & 70.8 & 267.3 & 289.2 & 60.8 & 37 & 0.2 & 5.4 & 25.6 & 16.2 \\
E4 & 222.2 & 318.8 & 661.9 & 162 & 0 & 2.6 & 7.5 & 20.8 & 14 \\
E5 & 48 & 358.9 & 304.6 & 23.3 & 41 & 0 & 5.1 & 23.4 & 14.9 \\
E6 & 52.7 & 389.4 & 349.2 & 37.1 & 0 & 2.1 & 7.9 & 23.8 & 15.7 \\
\hline
\end{tabular}

Source: Kombolcha Meteorological Station, Kombolcha, Amhara (Ethiopia).

Table 3. Description of plant materials.

\begin{tabular}{|c|c|c|c|c|c|}
\hline \multicolumn{2}{|c|}{ Variety } & \multirow{2}{*}{$\begin{array}{l}\text { Year of } \\
\text { release }\end{array}$} & \multicolumn{2}{|c|}{ Variety } & \multirow{2}{*}{$\begin{array}{l}\text { Year of } \\
\text { release }\end{array}$} \\
\hline Code & name & & Code & name & \\
\hline G1 & Mada-walabu & 2000 & G12 & Tsehay & 2011 \\
\hline G2 & Sofumar & 2000 & G13 & Hoganna & 2011 \\
\hline G3 & Tay & 2005 & G14 & Huluuka & 2012 \\
\hline G4 & Digalu & 2006 & G15 & Ogolcho & 2012 \\
\hline G5 & Alidoro & 2007 & G16 & Hidase & 2012 \\
\hline G6 & Gasay & 2007 & G17 & Mekelle-3 & 2012 \\
\hline G7 & Menze & 2007 & G18 & Sorra & 2013 \\
\hline G8 & Bolo & 2009 & G19 & Mekelle-4 & 2013 \\
\hline G9 & Danda'a & 2010 & G20 & Biqa & 2013 \\
\hline G10 & Kakaba & 2010 & G21 & King-bird & 2014 \\
\hline G11 & Shorima & 2011 & G22 & Honkollo & 2014 \\
\hline
\end{tabular}

Source: MoA, 2015 (Plant variety registration book, Addis Ababa, Ethiopia).

A total of twenty-two released Ethiopian bread wheat varieties (Table 3 ) were used. The materials were collected from different research centers of the country.

The experiment was laid-out using randomized completely block design (RCBD), replicated three times, at six locations in the main cropping season of 2016. A plot size of $3 \mathrm{~m}^{2}$ ( 6 rows of 2.5 meters length with a row spacing of $20 \mathrm{~cm}$ ) was used. Planting was carried out at all locations in the midweek of July. Fertilizer was applied uniformly for all experimental plots at the rate of $69 \mathrm{~N} / 46$
$\mathrm{P}_{2} \mathrm{O}_{5} \mathrm{Kg} \mathrm{ha}^{-1}$. Half of the recommended nitrogen fertilizer was applied at planting and the rest was applied at tillering while full dosage of the recommendation phosphorus fertilizer was applied at planting in the form of Diammonium phosphate (DAP). Seed rate $\left(125 \mathrm{Kg} \mathrm{ha}^{-1}\right)$ was used for each location. Weeding and rouging out practices were done for each experimental plot depending on the intensities of weed at each location. The four middle rows of each plot were harvested after varieties were fully matured. Grain yield (GY) ( $\mathrm{g} \mathrm{plot}^{-1}$ ) obtained from the 
central four rows was weighed using sensitive balance. The result was adjusted for the standard moisture contents of cereal crops $(12.5 \%)$, and converted in to ton ha- ${ }^{-1}$ for analysis.

\section{Data analyses}

Analysis of variance (ANOVA) for each environment and combined analysis of variance over environments were carried-out to examine the presence of genetic variation among bread wheat varieties for grain yield. The analyses were carried-out using Genstat 18th software. Duncan's Multiple Range Test (DMRT) was used to compare means among entries for grain yield (Steel and Torrie, 1980). ANOVA of the combined data expresses the observed mean yield $\left(Y_{i j}\right)$ of the $i^{\text {th }}$ genotype in the $j^{\text {th }}$ environment as:

$Y_{i j}=\mu+G_{i}+E_{j}+G E_{i j}+e_{i j}$

Where $\mu$ is the general mean; $G_{i}, E_{j}$, and $G_{i j}$ represent the effect of the genotype, environment, and the GE interaction, respectively; and $e_{i j}$ is the average of the random errors associated with the $r^{\text {th }}$ plot that receives the $i^{\text {th }}$ genotype in the $j^{\text {th }}$ environment.

AMMI and GGE biplot analysis were carried-out using Genstat software to examine the presence and magnitude of genotypic stability across environments.

\section{RESULTS AND DISCUSSION}

\section{AMMI Analysis}

The grain yield data were subjected to AMMI analysis which combines ANOVA with additive and multiplicative parameters in to single model (Gauch, 1988). The combined ANOVA for grain yield $\left(\mathrm{t} \mathrm{ha}^{-1}\right)$ revealed that the three sources of variation namely environments, genotypes, and GEI were significant at $p<0.001$ (Table 4). AMMI ANOVA depicted that sum square of additive effects of environment and genotype, and non-additive (GE interaction) effect explained $73 \%, 10 \%$, and $17 \%$ of the total treatment variation $(\mathrm{G}+\mathrm{E}+\mathrm{GEI})$ respectively (Table 4$)$. Hence, environment was the predominant source of variation which had big effect on yield of bread wheat genotypes. Following environmental effect, the GE interaction effect was stronger than the genotypic effect.

The large environmental effect for grain yield revealed that environments were diverse with large difference among environmental means. The maximum ( 4.7 ton ha-1) and minimum (2.3 ton ha-1) mean grain yield were recorded at E1 and E5, respectively (Table 5). Yield responses of each genotype at different locations varied. The mean grain yield over six environments ranged from
2.4 (G13) to 3.6 ton ha-1 (G1, G9 and G16) with a grand mean of 3.2 ton ha ${ }^{-1}$ (Table 5). In addition, G16, G19 and G21 genotypes revealed better grain yield performances across the testing environments (Table 5). Similar findings on the performances of bread wheat genotypes (Altay, 2012; Golkari et al., 2016; Mehari et al., 2015; Misganaw, 2016; Mohamed, 2013; Muhe and Assefa, 2011) and barley genotypes (Abay and Bjornstad, 2009; Jalata, 2011) across locations were reported.

Significant GE interaction indicates the relative change in rank of performances of genotypes across environments or the responses of bread wheat genotypes were not parallel in overall testing environments. Genotypic main effects (i.e. differences in mean yield between genotypes) provide the only relevant information when GE effects are absent or ignored (Yan and Kang, 2002). In agreement with this finding, using AMMI model, different authors reported responses of bread wheat genotypes for grain yield at varied environments (Akter et al., 2014; Golkari et al., 2016; Hagos and Abay, 2013; Rad et al., 2013; Tadesse and Abay, 2011; Temesgen et al., 2015).

The partitioning of the GE interaction sum square revealed that the first four interaction principal components analysis (IPCAs) were significant $(p \leq 0.01)$, explaining $95.2 \%$ of the total GE interaction sum square with $83.8 \%$ corresponding degree of freedoms and the remaining $4.8 \%$ considered as noise (Table 4). Almost similar result was reported by Mahmodi et al. (2011) for yield performances in bread wheat genotypes. The first IPCA explained $45.5 \%$ of the GE interaction sum of square. The second, third, and fourth IPCAs which explained $23.4 \%$, $15.3 \%$, and $11 \%$ of the total GE interaction sum of square, respectively. Therefore, based on the results, the best model called AMMI-4 was built from the first four significance IPCAs. The extract IPCAs are capable for providing basic information on the interaction effect even though the degrees decrease from the first to higher IPCAs. However, according to Gauch and Zobel (1996) and Zobel et al. (1988), the first two IPCAs are best enough to explain the interaction sum of squares. Therefore, for this experiment, the first two IPCAs with a total of $68.9 \%$ of GE interaction sum of square and $45.7 \%$ corresponding degree of freedom were used to explain the interaction effect. Similarly, Tadesse and Abay (2011) reported that the two IPCAs explained $67.2 \%$ of the total GE interactions on the study of sesame genotype evaluation for grain yield (Table 4). As GE interaction was significant, phenotypic stability of genotypes can be calculated (Farshadfar, 2008).

\section{Stability analysis by AMMI models}

The first two basic AMMI models (AMMI-1 and AMMI-2) were the best predictive models. The AMMI- 1 biplot (Zobel et al., 1988) is the most well-known and appealing 
Table 4. AMMI analysis of variance for grain yield $\left(\mathrm{t} \mathrm{ha}^{-1}\right)$ over six environments.

\begin{tabular}{lllllll}
\hline \multirow{2}{*}{ Source of variation } & \multirow{2}{*}{ DF } & \multirow{2}{*}{ SS } & \multirow{2}{*}{ MS } & \multicolumn{2}{c}{ Sum of squared (SS) explained (\%) } \\
\cline { 5 - 7 } & & & & SS & GE & GE cumulative \\
\hline Treatment & 131 & 370.4 & $2.83^{* * *}$ & & & \\
Genotypes (G) & 21 & 36.6 & $1.741^{* * *}$ & 10 & & \\
Environments(E) & 5 & 270.9 & $54.186^{* * *}$ & 73 & & \\
GE Interaction & 105 & 62.9 & $0.599^{* * *}$ & 17 & & \\
IPCA 1 & 25 & 28.6 & $1.146^{* * *}$ & & 45.5 & 45.5 \\
IPCA 2 & 23 & 14.7 & $0.641^{* * *}$ & & 23.4 & 68.9 \\
IPCA 3 & 21 & 9.6 & $0.457^{* * *}$ & & 15.3 & 84.2 \\
IPCA 4 & 19 & 6.9 & $0.363^{* * *}$ & & 11.0 & 95.2 \\
Residuals & 17 & 3.0 & $0.176^{\text {ns }}$ & & 4.8 & \\
Pooled Error & 252 & 36.2 & 0.144 & & & \\
Total & 395 & 432.0 & 1.094 & & & \\
\hline
\end{tabular}

*** Significant at 0.001 probability level, ns= non-significant, $\mathrm{SS}=$ sum of square, MS = mean of sum square.

Table 5. Mean grain yield of (ton ha-1) 22 bread wheat genotypes tested across 6 environments.

\begin{tabular}{|c|c|c|c|c|c|c|c|}
\hline \multirow{2}{*}{ Genotypes } & \multicolumn{6}{|c|}{ Grain yield (t/ha) } & \multirow[b]{2}{*}{ GM } \\
\hline & E1 & E2 & E3 & E4 & E5 & E6 & \\
\hline G1 & 5.5 & 2.5 & 4.3 & 3.0 & 2.9 & 3.3 & 3.6 \\
\hline G2 & 3.8 & 2.3 & 3.2 & 2.6 & 2.2 & 2.9 & 2.8 \\
\hline G3 & 4.6 & 2.5 & 4.0 & 3.5 & 1.3 & 2.9 & 3.1 \\
\hline G4 & 4.9 & 2.3 & 3.6 & 3.1 & 2.3 & 2.5 & 3.1 \\
\hline G5 & 4.3 & 2.4 & 3.3 & 2.7 & 1.6 & 2.8 & 2.9 \\
\hline G6 & 4.6 & 2.4 & 3.9 & 3.0 & 2.4 & 2.7 & 3.2 \\
\hline G7 & 4.6 & 2.2 & 3.8 & 2.9 & 1.8 & 3.2 & 3.1 \\
\hline G8 & 4.3 & 2.0 & 4.3 & 2.5 & 2.2 & 2.5 & 3.0 \\
\hline G9 & 4.1 & 2.6 & 4.7 & 3.0 & 3.6 & 3.4 & 3.6 \\
\hline G10 & 3.7 & 2.6 & 3.4 & 2.5 & 1.8 & 2.9 & 2.8 \\
\hline G11 & 4.5 & 2.6 & 4.2 & 2.4 & 2.2 & 2.8 & 3.1 \\
\hline G12 & 4.7 & 2.5 & 4.1 & 3.2 & 2.2 & 3.1 & 3.3 \\
\hline G13 & 3.2 & 1.5 & 3.3 & 2.4 & 1.9 & 2.0 & 2.4 \\
\hline G14 & 5.5 & 2.3 & 4.3 & 3.3 & 2.2 & 2.9 & 3.4 \\
\hline G15 & 5.5 & 3.2 & 3.5 & 3.3 & 2.4 & 2.9 & 3.5 \\
\hline G16 & 4.5 & 3.4 & 4.3 & 2.6 & 3.4 & 3.2 & 3.6 \\
\hline G17 & 6.4 & 2.3 & 4.0 & 2.6 & 2.3 & 3.0 & 3.4 \\
\hline G18 & 5.3 & 3.4 & 3.6 & 3.2 & 2.3 & 2.7 & 3.4 \\
\hline G19 & 4.9 & 3.3 & 3.9 & 2.5 & 2.5 & 3.9 & 3.5 \\
\hline G20 & 3.7 & 2.6 & 3.9 & 2.6 & 2.1 & 3.5 & 3.1 \\
\hline G21 & 5.8 & 2.2 & 3.6 & 3.0 & 3.4 & 2.5 & 3.4 \\
\hline G22 & 5.6 & 2.6 & 3.9 & 2.8 & 2.6 & 3.0 & 3.4 \\
\hline Mean & 4.7 & 2.5 & 3.9 & 2.9 & 2.3 & 2.9 & 3.2 \\
\hline CV (\%) & 10.0 & 13.4 & 8.8 & 11.9 & 17.0 & 12.4 & 11.8 \\
\hline $\operatorname{LSD}_{(0.05)}$ & 0.78 & 0.56 & 0.56 & 0.56 & 0.66 & 0.6 & 0.7 \\
\hline
\end{tabular}

GM (Genotypic Mean), CV (Coefficient of Variation), LSD (Least Significant Difference).

component of AMMI model. Its abscissa (x-coordinate) represents the main effects ( $G$ and $E)$ and its ordinate $(y-$ coordinate) represents the IPCA-1 scores. In Figure 1, the IPCA-1 scores for genotypes (G1 to G22) and 


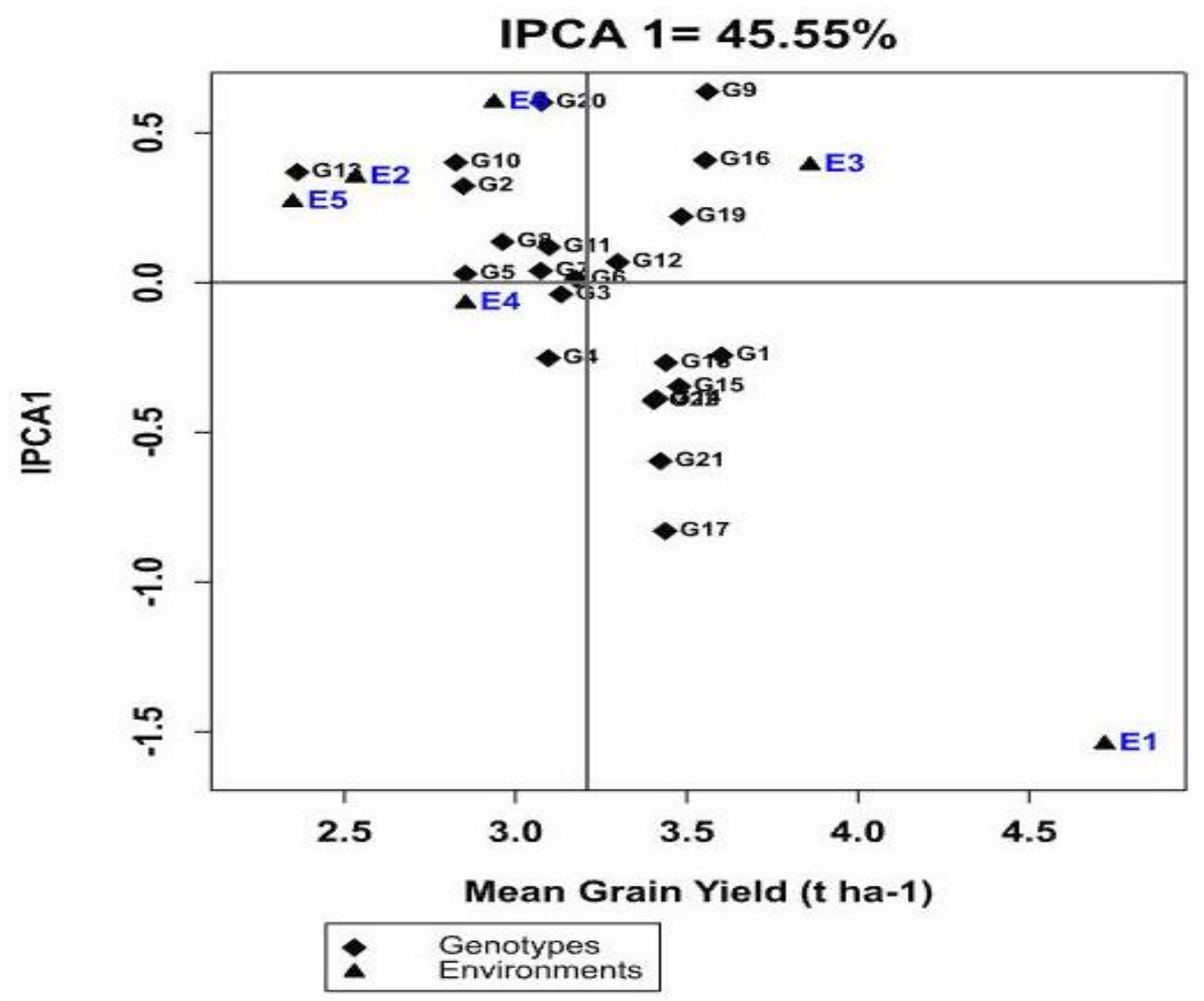

Figure 1. AMMI-1 biplot for grain yield (t ha-1) of 22 bread wheat genotypes at six environments.

environments (E1 to $E 6)$ were plotted against the main effects (genotype and environment grain yield means). Figure 1 therefore accounted for $90.74 \%$ of the total treatment sum of square $(\mathrm{G}+\mathrm{E}+\mathrm{GE})$, which was reasonably enough to explain the GE interactions and main effects. This result was similar with the finding of Misganaw (2016) and Akter et al. (2014) on wheat and rice crops respectively. Genotypes and environments on the same parallel line relative to ordinate have similar grain yields and genotypes and environments on the right side of the midpoint (mean grain yield) of this axis have higher mean grain yield than those found on the left side. AMMI1 biplot (Figure 1) depicted that Genotype G9 and G16 were generally exhibited high mean yield with high main (additive) effect and plotted with E3, indicating their specific adaptability to E3. Genotype G19 recorded high mean grain yield coupled with small positive IPCA-1scores indicating its stability in all testing environments. G17 and G21 genotypes exhibited high mean yield and associated with negative IPCA-1 score and plotted with E1, indicating its suitability to $E 1$ and similar environments. On the other hand, G12, G6, G3, G7, and G11 genotypes were laid near to the biplot origin; showing their agronomic stability in all the testing environments. Genotype G1, G18 and G15 recorded small negative IPCA1 scores associated with high mean grain yield indicating these genotypes performed well in the testing environments. Similar results have been reported by different authors in earlier studies (Akter et al., 2014; Golkari et al., 2016; Temesgen et al., 2015). As shown in Figure 1, environments were variable for both interaction and main effects. Among the testing environments, E1 recorded the largest negative IPCA-1 scores and the highest environmental mean grain yield $\left(4.7 \mathrm{t} \mathrm{ha}^{-1}\right)$ relative to the rest of the environments. $\mathrm{E} 6 \mathrm{had}$ largest positive IPCA-1 scores with below average mean grain yield. These two environments were highly interactive environments which contributed the largest interaction effects. On the other hand, E4 scored the least negative IPCA-1 score associated with below average mean grain yield, indicating its minimal contribution to discriminate the tested bread wheat genotypes. The other environments were found in between the highest and the lowest interactive environments. The tested bread wheat genotypes relatively explained their genetic potential at E1 and E3, providing above average grain yield. These two environments are classified as high yielding (high potential) environments whereas, E2, E4, E5, and E6 recorded below average grain yield, and hence clustered under low yielding (poor) environments (Figure 1). In agreement with this finding, researchers have reported the 


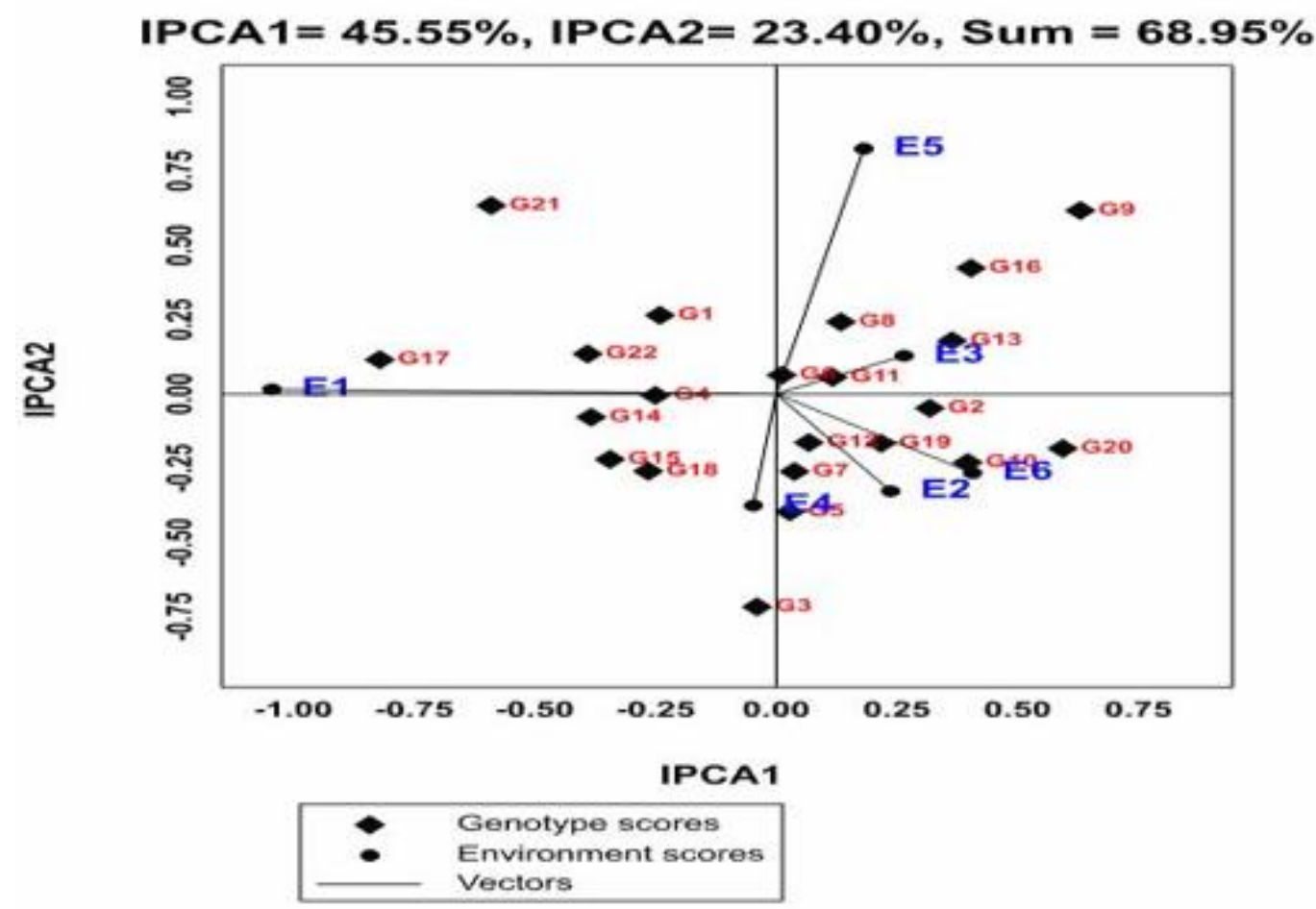

Figure 2. AMMI-2 Biplot for grain yield (ton ha-1) showing the Interactions of IPCA1 and IPCA2 of both genotype and environment scores.

performances of bread wheat genotypes in variable environments (Muhe and Assefa, 2011; Temesgen et al., 2015).

According to Vargas and Crossa (2000), AMMI-2 biplot was generated by using genotypic and environmental scores of the first two IPCAs in which both genotypes and environments are displayed simultaneously (Figure 2). In the plotting of AMMI-2 biplot, Purchase (1997) pointed out that the closer the genotypes scores to the center of the biplot the more stable they are.

In AMMI 2 biplot (Figure 2), the environmental scores are joined to the origin by side lines called vectors. Environments with short vectors did not exert strong interaction effects while those environments that have long vectors located away from the origin exert strong interaction effects. Thus, in this study E1, E5 and E6 had long vectors and high IPCA scores, and then contributed more interaction effects while E2, E3, E4 had relatively short vectors by which they did not exert strong interactive force (minimal discriminating power). Especially, E3 had the shortest vector as compared to the rest environments and recorded above average mean grain yield, therefore, it is the most ideal environment for the tested bread wheat genotypes. Similar results were reported by Golkari et al. (2016) and Neisse et al. (2018).

AMMI -2 biplot revealed that G9, G17 and G21 were located farthest from the origin of the biplot which indicated the most responsive (interactive) genotypes, contributed the highest interaction effects, even had high mean grain yield performances. The genotypes occurring close together on the biplot origin will tend to have similar yield responses in all testing environments, while those located far apart may indicated either differ in mean grain yield or show different pattern of response over the environments. $\mathrm{G} 6, \mathrm{G} 11, \mathrm{G} 12$, and $\mathrm{G} 4$ were close to the origin and hence insensitive for environmental change.

\section{GGE biplot analysis}

According to Yan et al. (2000), the first two Principal Components (PCs) are used to produce a two-dimensional graphical display of genotype by environment interaction called GGE biplot analysis. For this investigation, the polygon view (Figure 3) showed "which-won-where" pattern of the ME trials data. The fitted GGE-biplot model indicated that the first two PCs explained $70.5 \%$ of variation for $\mathrm{G}+\mathrm{GE}$ (Figure 3). The polygon view of the GGE biplot was drawn by connecting the vertices genotypes with straight lines so that all other genotypes were contained within the polygon. Genotypes G9, G20, G13, G3, G17, G1 and G16 were displayed at the vertex points of the biplot (Figure 3). These genotypes were the best or poorest in some or all of the environments because they were far from the origin of biplot (Yan and Kang, 2002). Especially, G9, G16, G17, G13 were more responsive 


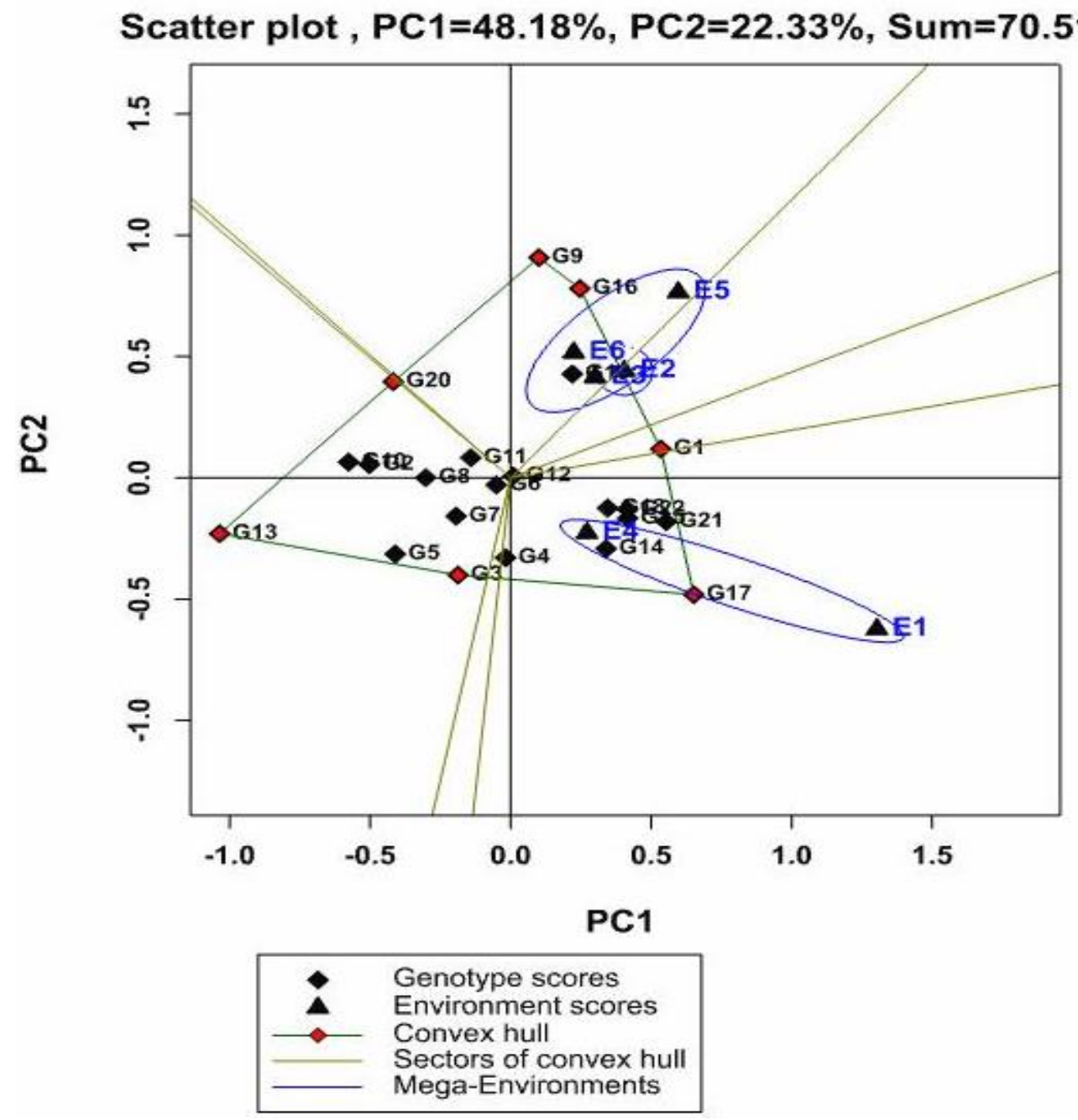

Figure 3. The which-won-where polygon view of GGE-biplot for grain yield of 22 bread wheat genotypes over six environments.

for environmental change because they were displaced farthest from the origin of the biplot; considered as specifically adapted genotypes.

The perpendicular lines which were drawn in each side of the polygon divided the biplot into seven sectors. The six testing environments fall into the three sectors, and all sectors also contained genotypes. Among the sectors, where the testing environments falling were grouped into: $\mathrm{E} 5, \mathrm{E} 6$ and $\mathrm{E} 3$ as one group, E1 and E4 as second group and E2 as third group. In each sector, the winner genotypes appeared but G9 was the winner genotype for the three environments (E5, E6 and E3) even if other options like G16 and G19 were available for such environments. Genotype G17 was the winner for the second sector called E1 and E4; other options such as G21, G14, and G15 genotypes were also contained within this sector. The third sector contained environment E2 in which $\mathrm{G} 19$ was best fit genotype.

The GGE biplot analysis clustered the six environments into two Mega-Environments, thus; E5, E6, E3, and E2 were grouped under one Mega-Environment, and E1 and E4 as other Mega-Environment (Figure 4). Genotypes G9, G16 and G19 were best fit for E2, E3, E5 and E6 since they were clustered into one Mega-Environment and in one Micro-Environment/sector. As shown in the Figure 3, genotypes $\mathrm{G} 6$ and $\mathrm{G} 12$ were found near to the origin and have above average grain yield, which were good for all testing environments, however, genotype G6 is late maturing and thus needs extended rainfall.

According to the description of Yan (2001), the yield performances and stability of bread wheat genotypes as shown in Figure 4, where average tester coordinate (ATC $x$-axis) or average environment axis (AEC) passes through the biplot origin, represented by single-arrowed solid blue 


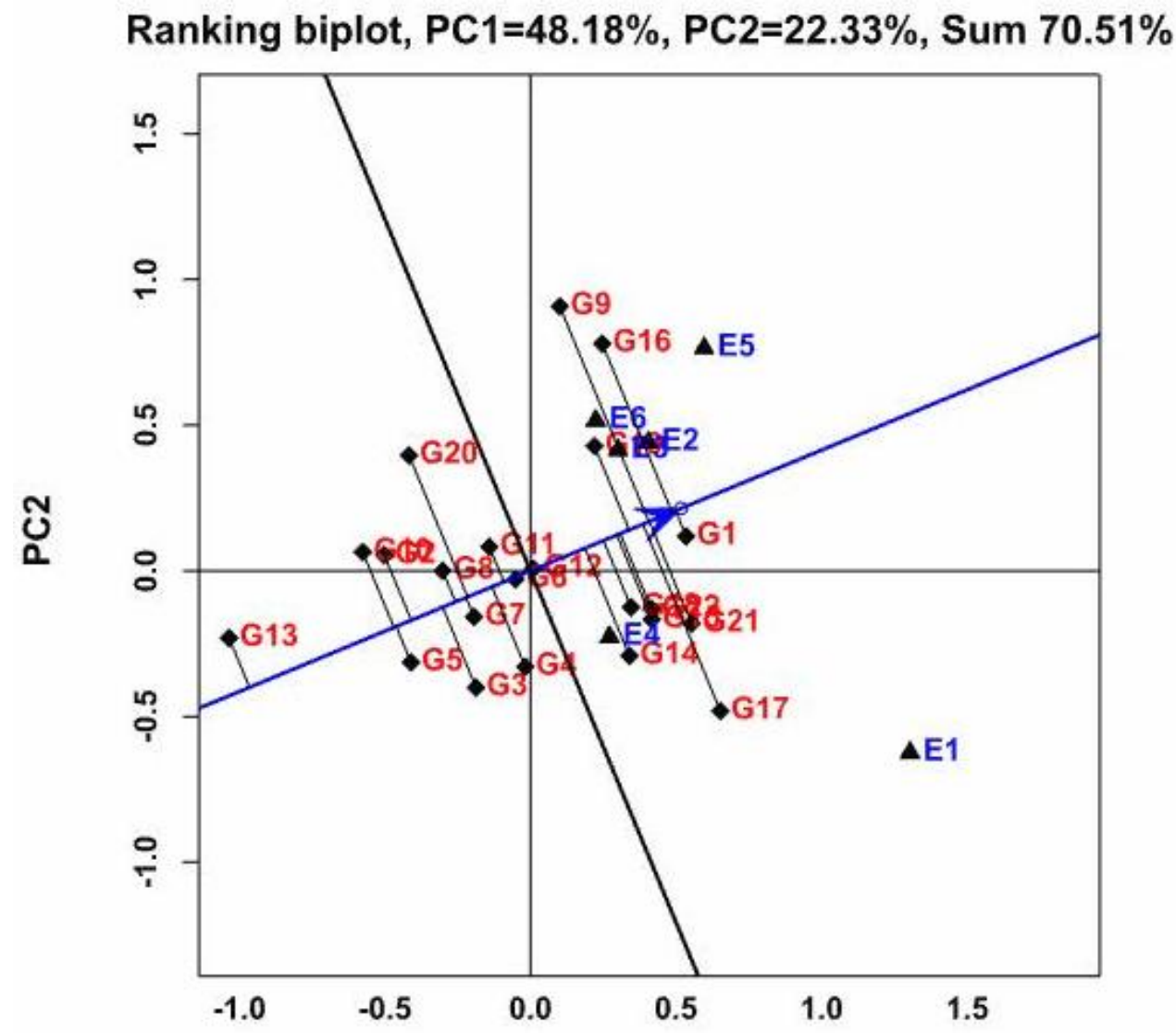

\section{PC1}

bread wheat genotypes over six environments.

line, and the marker of the average environments, which is defined by the average of PC1and PC2 scores over all environments. The oval shape indicated the positive ends of ATC-x axis or the positive direction of the tester axis. Closeness to the circle indicates higher mean yield. The ATC-y axis (represented by solid black line) passes through the plot origin and was perpendicular to ATC-x axis called perpendicular line which represents the stability of genotypes. Either direction away from the biplot origin, on this axis, indicates greater $\mathrm{G} \times \mathrm{E}$ interaction and reduced stability (Yan and Hunt, 2002). The average yield of the genotypes was approximated by the projections of their markers through the ATC-x axis. Thus, genotype G1 had the highest average yield, and G13 recorded the lowest (Figure 4).

The lines parallel to the ATC-y axis helps ranking of genotypes based on their average yield and the stability of genotypes was measured by the absolute length of their projection to the ATC-y axis. The greater the absolute length of the projection of a genotype, the less stability it had and vise versa (Yan, 2001). Thus, Genotypes G1, G6 and G12 were the most stable genotypes; as it were located almost on the ATC-x axis and had a near zero projection onto the ATC-y axis. This indicates that its ranks were consistent across testing environments within this mega-environment. In contrast, G9 and G17 were the two least stable genotypes with above average mean yield performance (Figure 4). According to Yan et al. (2000), E4, E3, E2 were the most representative environments (had less projection on to ATC-x axis) while E1 and E5 were less representative (had large projection on to ATC-x axis) and the most discriminative environments, E6 was found 
between the two extreme environments. The discriminating power of E2, and E3 were larger than E4 (Figure 4).

\section{Conclusions}

The significant effects of GE interaction indicated that, the presence of substantial differences in the relative performance of genotypes at different locations.

AMMI-1 biplot indicated that G9 and G16 generally exhibited high mean yield with positive IPCA-1 score were identified to specifically adapted to E3. G17 was also exhibited high mean yield and high negative IPCA score, which was fitted genotype for E1. G19 gave high mean grain yield and relatively small positive IPCA-1 scores which was good for all environments.

AMMI-2 biplot revealed that G9, G19 and G21 genotypes were located far away from origin which exhibited the most unstable genotypes. With respects to environments, E1, E5 and E6 were the most discriminative (interactive) environments while the remaining environments; E2, E3 and E4 exhibited the least interactive environment for bread wheat production.

Based on "which-won-where" procedures of GGE biplot analysis, the analysis clustered environments under two Mega-Environments which include: E1 and E4 (Mega environment-I), and E2, E3, E5 and E6 (MegaEnvironment-II). Thus, E9, E16 and E19 were the best adapted genotypes for the four environments (MegaEnvironment-II). G17 was the winner genotype for environments E1 and E4 (Mega-Environment-I); even when other options such as G21, G14 and G15 genotypes were available.

\section{CONFLICT OF INTEREST}

The authors declare that they have no conflict of interest.

\section{REFERENCES}

Abate, F., Mekbib, F., \& Dessalegn, Y. (2015). GGE Biplot analysis of multi-environment yield trials of durum wheat (Triticum turgidum Desf) genotypes in North Western Ethiopia. American Journal of Experimental Agriculture, 8(2), 120-129.

Abay, F., \& Bjornstad, A. (2009). Identifying optimal testing environments of barley yield in the Northern Highlands of Ethiopia by Biplot analysis. Journal of the Dry Lands, 2(1), 4047.

Akter, A., Jamil, H. M., Umma, K. M., Islam, M. R., Hossain, K., \& Mamunur, R. M. (2014). AMMI biplot analysis for stability of grain yield in hybrid rice (Oryza sativa L.). Journal of Rice Research, 2(2), 10-13.

Altay, F. (2012). Yield stability of some Turkish winter wheat (Triticum aestivum L.) genotypes in the western transitional zone of Turkey. Turkish Journal of Field Crops, 17(2), 129-134.

Ayalew, H., Wondale, L., \& Teshager, A. (2014). GGE biplot analysis on the performance of wheat genotype for hectolitre weight and mega environments identification in north western Ethiopia. Australian Journal of Crop Science, 8(10), 14351440.

Bacha, T., Alemerew, S., \& Tadesse, Z. (2015). Genotype X Environment interaction and yield stabliity of breade wheat (Triticum Eastivum L.) genotype in Ethiopia using the AMMI analisis. Journal of Biology, Agriculture and Healthcare, 5(11), 129-140.

Bradu, D., \& Gabriel, K. R. (1978). The biplot as a diagnostic tool for models of two- way tables. Technometrics, 20(1), 47-68.

Ceccarelli, S. (2012). Plant breeding with farmers-a technical manual. Aleppo, Syria: ICARDA.

Crossa, J. (1990). Statistical Analysis of Multilocation Trials. Advances in Agronomy, 44, 55-85.

Crossa, J., Gauch, H. G., \& Zobel, R. W. (1990). Additive main effects and multiplicative interaction analysis of two international maize cultivar trials. Crop Science, 30(3), 493500.

CSA (2016). The Federal Democratic Republic of Ethiopia Central Statistical Agency Report on area and production of major (Vol. I (584)).

DeLacy, I. H., Basford, K. E., Cooper, M., Bull, J. K., \& McLaren, C. G. (1996). Analysis of multi-environment trials-an historical perspective. Plant adaptation and crop improvement, 39124.

Eberhart, S. A., \& Russell, W. A. (1966). Stability Parameters for Comparing Varieties. Crop Science, 6(1), 36-40.

Fan, X., Kang, M. S., Chen, H., Zhang, Y., Tan, J., \& Xu, C. (2007). Yield stability of maize hybrids evaluated in multienvironment trials in Yunnan, China. Agronomy Journal, 99(1), 220-228.

Farshadfar, E., Mohammadi, R., Aghaee, M., \& Vaisi, Z. (2012). GGE biplot analysis of genotype $\times$ environment interaction in wheat-barley disomic addition lines. Australian Journal of Crop Science, 6(6), 1074-1079.

Finlay, K. W., \& Wilkinson, G. N. (1963). The analysis of adaptation in a plant-breeding programme. Australian Journal of Agricultural Research, 14(6), 742-754.

Francis, T. R., \& Kannenberg, L. W. (1978). Yield stability studies in short-season maize. I. A descriptive method for grouping genotypes. Canadian Journal of Plant Science, 58(4), 10291034.

Gauch, H. G. (1988). Model Selection and Validation for Yield Trials with Interaction. Biometrics, 44(3), 705-715.

Gauch, H. G., \& Zobel, R. W. (1988). Predictive and postdictive success of statistical analyses of yield trials. Theoretical and Applied Genetics, 76(1), 1-10.

Gauch, H. G., \& Zobel, R. W. (1996). Optimal replication in selection experiments. Crop Science, 36(4), 838-843.

Gebru, H., Hailemariam, A., \& Belay, T. (2011). Genotype by environment interaction and grain yield stability of early maturing bread wheat (Triticum aestivum L.) genotypes in the drought prone areas of Tigray region, northern Ethiopia. Ethiopian Journal of Applied Science and Technology, 2(1), 51-57.

Golkari, S., Hagparast, R., Roohi, E., Mobasser, S., Ahmadi, M. M., Soleimani, K., Khalilzadeh, G., Abedi-Asl, G., \& Babaei, T. (2016). Multi-environment evaluation of winter bread wheat genotypes under rainfed conditions of Iran-using AMMI model. Crop Breeding Journal, 4(6), 17-31. 
Hagos, H. G., \& Abay, F. (2013). AMMI and GGE biplot analysis of bread wheat genotypes in the northern part of Ethiopia. Journal of Plant Breeding and Genetics, 1(1), 12-18.

Haldane, J. B. (1946). The interaction of nature and nurture. Annals of Eugenics, 13(1), 197-205.

Jalata, Z. (2011). GGE-biplot Analysis of Multi-environment Yield Trials of Barley (Hordeium vulgare L.) Genotypes in South eastern Ethiopia Highlands. International Journal of Plant Breeding and Genetics, 5(1), 59-75.

Kempton, R. A. (1984). The use of biplots in interpreting variety by environment interactions. The Journal of Agricultural Science, (103), 123-135.

Mahmodi, N., Yaghotipoor, A., \& Farshadfar, E. (2011). AMMI stability value and simultaneous estimation of yield and yield stability in bread wheat (Triticum aestivum L.). Australian Journal of Crop Science, 5(13), 1837.

Mehari, M., Tesfay, M., Yirga, H., Mesele, A., Abebe, T., Workineh, A., \& Amare, B. (2015). GGE biplot analysis of genotype-by-environment interaction and grain yield stability of bread wheat genotypes in South. Communication in Biometry and Crop Science, 10(1), 17-26.

Misganaw, F. (2016). Stability Analysis in Bread Wheat (Triticum aestivum L) Genotypes in North-western Ethiopia. East African Journal of Sciences, 10(1), 15-22.

Mohamed, N. E. M. (2013). Genotype by environment interactions for grain yield in bread wheat (Triticum aestivum L.). Journal of Plant Breeding and Crop Science, 5(7), 150-157.

Mohamed, N. E., \& Ahmed, A. A. (2013). Additive main effects and multiplicative interaction (AMMI) and GGE-biplot analysis of genotype environment interactions for grain yield in bread wheat (Triticum aestivum L.). African Journal of Agricultural Research, 8(42), 5197-5203.

Mohammadi, M., Sharifi, P., Karimizadeh, R., Jabbar, J. A., Khanzadeh, H., Hosseinpour, T., Mohammadi, P., \& Rous, M. (2015). Stability of grain yield of durum wheat genotypes by AMMI model. Agriculture and Forestry, 61(3), 181-193.

Mohammadi, R., Armion, M., Sadeghzadeh, D., Amri, A., \& Nachit, M. (2011). Analysis of Genotype-by-Environment Interaction for Agronomic Traits of Durum Wheat in Iran Analysis of Genotype-by-Environment Interaction for Agronomic Traits of Durum Wheat in Iran. Plant Production Science, 14(1), 15-21.

Muhe, K., \& Assefa, A. (2011). Genotypes X environment interaction in bread wheat (Triticum aestivum L.) cultivar development in Ethiopia. International Research Journal of Plant Science, 2(10), 317-322.

Neisse, A. C., Kirch, J. L., \& Hongyu, K. (2018). AMMI and GGE Biplot for genotype $\times$ environment interaction: a medoid-based hierarchical cluster analysis approach for high-dimensional data. Biometrical Letters, 55(2), 97-121.

Perkins, J. M., \& Jinks, J. L. (1968). Environmental and Genotype-Environmental Components of Variability III. Multiple Lines and Crosses. Heredity, 23, 339-356.

Pinthus, M. J. (1973). Estimate of genotypic value: A proposed method. Euphytica, 22(1), 121-123.

Purchase, J. L. (1997). Parametric analysis to describe genotype by environment interaction and yield stability in winter wheat. Orange Free State, Bloemfontein, South Africa.
Rad, M. R. N., Kadir, M. A., Rafii, M. Y., Jaafar, H. Z. E., \& Naghavi, M. R. (2013). Genotype $\times$ environment interaction by AMMI and GGE biplot analysis in three consecutive generations of wheat (Triticum aestivum) under normal and drought stress conditions. Australian Journal of Crop Science, 7(7), 956-961.

Romagosa, I., \& Fox, P. (1993). Genotype by Environment Interactions and Adaptation. In I. Hayward, M.D, Bosenmark, N.O. and Romagosa (Ed.), Plant Breeding Principles and Prospects (pp. 373-390). London: Chapman and Hall.

Sanchez-garcia, M., Álvaro, F., Martín-sánchez, J. A., Sillero, J. C., Escribano, J., \& Royo, C. (2012). Field Crops Research Breeding effects on the genotype $\times$ environment interaction for yield of bread wheat grown in Spain during the 20th century. Field Crops Research, 126, 79-86.

Shafii, B., \& Price, W. J. (1998). Analysis of Genotype-byEnvironment Interaction Using the Additive Main Effects and Multiplicative Interaction Model and Stability Estimates. Journal of Agricultural Biological and Environmental Statistics, 3(3), 335-345.

Shukla, G. K. (1972). Some statistical aspects of partitioning genotype-environmental components of variability. Heredity, 29(2), 237-245.

Tadesse, H., \& Abay, F. (2011). Additive Main Effects and Multiplicative Interactions Analysis of Yield Performance of Sesame Genotypes across Environments in Northern Ethiopia. Journal of the Dry Lands, 4(1), 259-266.

Temesgen, M., Alamerew, S., \& Eticha, F. (2015). GGE Biplot Analysis of Genotype by Environment Interaction and Grain Yield Stability of Bread Wheat Genotypes in South East Ethiopia. World Journal of Agricultural Sciences, 11(4), 183190.

Yan, W. (2001). GGE biplot -A Windows Application for graphical analysis of multi-environment trial data and other types of twoway data. Agronomy Journal, 93, 1111-1118.

Yan, W., \& Hunt, L. A. (2002). Biplot Analysis of Diallel Data. Crop Science, 42, 21-30.

Yan, W., \& Kang, M. (2002). GGE biplot analysis: A graphical tool for breeders, geneticists' agronomists. CRC Press, Boca Raton, Florida.

Yan, W., Hunt, L. A., Sheng, Q., \& Szlavnics, Z. (2000). Cultivar evaluation and mega-environment investigation based on the GGE biplot. Crop Science, 40(3), 597-605.

Yan, W., Kang, M. S., Ma, B., Woods, S., \& Cornelius, P. L. (2007). GGE Biplot vs. AMMI analysis of genotype-byenvironment data. Crop Science Society of America, 47, 641653.

Zobel, R. W., Wright, M. J., \& Gauch, H. G. (1988). Statistical analysis of a yield trial. Agronomy Journal, 80, 388-393. 